\title{
Basis for Defective Responses of Rheumatoid Arthritis Synovial Fluid Lymphocytes to Anti-CD3 (T3) Antibodies
}

Martin Lotz, Constantine D. Tsoukas, Charles A. Robinson, Charles A. Dinarello, * Dennis A. Carson, and John H. Vaughan Department of Basic and Clinical Research, Scripps Clinic and Research Foundation, La Jolla, California 92037; and *Tufts University School of Medicine, Boston, Massachusetts 02112

\begin{abstract}
Synovial fluid mononuclear cells (SFMC) from patients with active rheumatoid arthritis characteristically respond poorly to mitogens. In this study, mitogenic antibodies reactive with the CD3(T3) antigen on human T lymphocytes were used to analyze the basis for the deficiency. OKT3-induced proliferation and release of interleukin 1 (IL-1) and interleukin 2 (IL-2) from SFMC were depressed in all patients. Purified IL-1 or recombinant IL2 restored proliferative responses in SFMC and increased IL-2 receptor density. Exogenous IL-1 also enhanced IL-2 release.

Fractionation of SFMC supernatants on phosphocellulose columns revealed the presence of $I L-1$ and a potent $I L-1$ inhibitor. The monocyte-derived IL-1 inhibitor blocked IL-1-dependent responses of normal peripheral blood lymphocytes to OKT3, but had no effect on IL-2-dependent events. These results suggest that IL-1 inhibitor(s) in SFMC impair(s) OKT3-induced mitogenesis by interfering with the effects of IL-1 on T lymphocytes. The net result is deficient IL-2 secretion, IL-2 receptor expression, and impaired cellular proliferation. This novel inhibitory circuit provides a rational explanation for the diminished function of synovial fluid $T$ lymphocytes in rheumatoid arthritis patients.
\end{abstract}

\section{Introduction}

The proliferative response of rheumatoid arthritis (RA) ${ }^{1} \mathrm{~T}$ lymphocytes to stimulation with plant mitogens is deficient (1-3). Peripheral blood lymphocytes from patients with active and severe disease are moderately hyporesponsive (1), whereas the defect of synovial fluid lymphocytes is much more profound ( 2 , 3). The basis for this abnormality is unknown, and is difficult to study with nonspecific plant mitogens, because they react with sugar residues not selectively expressed on T lymphocytes $(4,5)$. Furthermore, phytohemagglutinin (PHA) reacts with at least two distinct surface molecules on $T$ cells, the antigen receptor-T3 complex and the sheep red blood cell receptor $(5,6)$. Both these receptors are triggers for $\mathrm{T}$ cell activation.

This is Publication No. 3926BCR from the Research Institute of Scripps Clinic.

Address reprint requests to Dr. Lotz, Department of Basic and Clinical Research-BCR4, Scripps Clinic and Research Foundation, 10666 North Torrey Pines Road, La Jolla, CA 92037. 1986

Received for publication 8 July 1985 and in revised form 22 April

1. Abbreviations used in this paper: IL-1 and IL-2, interleukins 1 and 2; PBMC, peripheral blood mononuclear cell(s); PHA, phytohemagglutinin; RA, rheumatoid arthritis; SFMC, synovial fluid mononuclear cell(s).

J. Clin. Invest.

(c) The American Society for Clinical Investigation, Inc. 0021-9738/86/09/0713/09 \$1.00

Volume 78, September 1986, 713-721
Monoclonal antibodies against the CD3(T3) molecular complex, which is exclusively present on $\mathrm{T}$ lymphocytes $(7,8)$, are potent mitogens (9). The cellular interactions leading to antiCD3-induced $\mathrm{T}$ cell proliferation are well defined. The antiCD3 antibodies bind specifically to their corresponding antigen on the $\mathrm{T}$ cell surface, whereas the $\mathrm{Fc}$ portion binds to $\mathrm{Fc}$ receptors on monocytes. Both events are required for anti-CD3-triggered $\mathrm{T}$ cell activation (10-12). The $\mathrm{T}$ cell-monocyte interaction, presumably by a cross-linking event, induces interleukin 1 (IL-1) responsiveness and the presence of IL-1 is important for expression of receptors for interleukin 2 (IL-2), the release of IL-2, and ultimately IL-2-dependent cellular proliferation $(13,14)$.

In the present investigation we have used anti-CD3 antibodies in order to examine these activation events in lymphocytes from RA blood and synovial fluid. The results indicate that the depressed mitogenic responses of RA lymphocytes are mediated predominantly by a specific inhibitor of IL-1.

\section{Methods}

Patient selection and characteristics. Heparinized peripheral blood was obtained from 22 healthy volunteers and patients with classical RA according to American Rheumatism Association criteria (15). Paired synovial fluid and peripheral blood samples were obtained from 19 patients with RA. Their biological parameters and medications are shown in Table I. An additional nine RA synovial fluid specimens came from subjects whose blood was not available.

Lymphocyte isolation and culture. Mononuclear cells were isolated from synovial fluid and peripheral blood by Ficoll-Hypaque densitygradient sedimentation (16). Lymphocytes were cultured in RPMI-1640 medium supplemented with $5 \%$ heat-inactivated $\left(56^{\circ} \mathrm{C}, 30 \mathrm{~min}\right)$ fetal bovine serum, $100 \mathrm{U} / \mathrm{ml}$ penicillin, $100 \mu \mathrm{g} / \mathrm{ml}$ streptomycin, $2 \mathrm{mM} \mathrm{L}-$ glutamine (all from M.A. Bioproducts, Los Angeles, CA) and $12.5 \mu \mathrm{g} /$ $\mathrm{ml}$ polymyxin B. Aliquots of cells $\left(200 \mu \mathrm{l}\right.$ each) at a density of $10^{6} / \mathrm{ml}$ were distributed among the wells of microtiter trays (Costar No. 3596, Data Packaging Corp., Cambridge, MA), and were incubated for $72 \mathrm{~h}$ in an atmosphere of $5 \% \mathrm{CO}_{2}$-air in the presence or absence of the antiCD3 antibodies, OKT3 $(0.001-10 \mathrm{ng} / \mathrm{ml})$ or Leu $4(0.01-200 \mathrm{ng} / \mathrm{ml})$. [Methyl $-{ }^{3} \mathrm{H}$ ]thymidine $(1 \mu \mathrm{Ci} /$ well $)$ was added during the last $4 \mathrm{~h}$ of incubation. The cells were collected on glass fiber filters, and radioactivity was assessed by liquid scintillation spectrometry.

Sources of $I L-1, I L-2$, and antibodies. The IL-1 used in these studies was purified from cultures of human adherent blood monocytes as previously described using a combination of immunoadsorption and gel filtration (17). When separated by charge (chromatofocusing or isoelectric focusing), this IL-1 contained predominantly the pI 7 form. The purified material was assayed for the production of fever in rabbits and for lymphocyte-activating factor (LAF). The IL-1 used in these studies contained $\sim 100 \mathrm{U} / \mathrm{ml}$ where a unit is defined as the amount of IL- $1 / \mathrm{ml}$ which doubled the proliferative responses of murine thymocytes to suboptimal concentrations of PHA. The antibody to IL-1 has been described previously (18). It was absorbed against immobilized human serum and human mononuclear cells at $4^{\circ} \mathrm{C}$. It did not react with human IL-2, B cell growth factor, human $\mathrm{C} 5$, or interferons- $\alpha$ or $-\gamma$. A 1:100 dilution of the absorbed anti-IL-1 neutralized $100 \mathrm{U} / \mathrm{ml}$ of IL-1 in the standard 


\begin{tabular}{|c|c|c|c|c|c|c|c|c|c|}
\hline \multirow[b]{3}{*}{ Patient } & \multirow[b]{3}{*}{ Sex } & \multirow[b]{3}{*}{ Age } & \multirow[b]{3}{*}{ ESR } & \multirow{3}{*}{$\begin{array}{l}\text { Disease } \\
\text { duration }\end{array}$} & \multirow[b]{3}{*}{ Medications } & \multicolumn{4}{|c|}{ Day 3 proliferation } \\
\hline & & & & & & \multicolumn{2}{|l|}{ PBMC } & \multicolumn{2}{|l|}{ SFMC } \\
\hline & & & & & & Contr & OKT3 & Contr & OKT3 \\
\hline & & & & $y r$ & & $c p m$ & $c p m$ & $c p m$ & $c p m$ \\
\hline B.A. & Female & 63 & 68 & 12 & NSAID, prednisone & 341 & 24,536 & 294 & 5,220 \\
\hline V.M. & Female & 52 & 59 & 16 & NSAID & 673 & 59,310 & 559 & 7,818 \\
\hline D.M. & Female & 63 & 69 & 6 & NSAID, plaquenil & 2,460 & 83,969 & 522 & 9,395 \\
\hline E.S. & Male & 64 & 48 & 11 & Prednisone, NSAID & 912 & 122,525 & 3,319 & 11,861 \\
\hline H.W. & Male & 68 & 32 & 7 & NSAID & 3,374 & 82,206 & 1,640 & 23,613 \\
\hline J.S. & Female & 62 & 91 & 4 & NSAID & 2,488 & 92,937 & 634 & 24,342 \\
\hline M.F. & Female & 48 & 52 & 10 & NSAID, gold & 1,096 & 56,382 & 1,936 & 14,364 \\
\hline E.D. & Female & 72 & 117 & 8 & D-Pencillamine & 1,930 & 49,387 & 2,876 & 12,392 \\
\hline R.P. & Female & 64 & 96 & 12 & NSAID & 876 & 38,492 & 1,392 & 9,845 \\
\hline L.J. & Male & 52 & 83 & 3 & Gold, prednisone, NSAID & 218 & 42,836 & 1,231 & 19,348 \\
\hline L.C. & Female & 54 & 46 & 8 & Prednisone, NSAID & 2,046 & 68,392 & 1,796 & 16,839 \\
\hline L.K. & Female & 28 & 108 & 5 & $\begin{array}{l}\text { D-penicillamine, } \\
\text { plaquenil, prednisone, } \\
\text { NSAID }\end{array}$ & 3,151 & 39,569 & 2,046 & 14,834 \\
\hline L.K. & Female & 65 & 48 & 14 & Plaquenil, NSAID & 734 & 58,304 & 1,124 & 8,837 \\
\hline J.D. & Male & 43 & 104 & 1 & NSAID, gold & 782 & 148,580 & 582 & 77,988 \\
\hline P.C. & Female & 63 & 62 & 8 & NSAID & 1,832 & 42,893 & 1,413 & 17,922 \\
\hline M.Z. & Male & 65 & 34 & 11 & Plaquenil, NSAID & 1,123 & 39,845 & 1,780 & 9,438 \\
\hline B.G. & Female & 60 & 73 & 15 & Cytoxan & 1,481 & 79,445 & 2,034 & 13,942 \\
\hline P.M. & Male & 63 & 82 & 8 & Imuran, NSAID & 987 & 56,832 & 1,684 & 12,396 \\
\hline D.E. & Male & 66 & 45 & 3 & D-Pencillamine, NSAID & 2,033 & 68,794 & 986 & 16,341 \\
\hline
\end{tabular}

Abbreviations: ESR, erythrocyte sedimentation rate; NSAID, nonsteroidal anti-inflammatory drugs.

thymocyte assay. Recombinant IL-2 produced in Escherichia coli (19) was generously provided by Cetus Corp. (Emeryville, CA). IL-2 lot LP 227 was shown by the supplier to be $98 \%$ pure by sodium dodecyl sulfatepolyacrylamide gel electrophoresis and contained $<0.02 \mathrm{ng} / \mathrm{mg}$ endotoxin. One unit of IL-2 is the amount producing half maximal growth of an IL-2-dependent cell line (20). Monoclonal anti-IL-2 antibody (DMS-3) (21) was kindly provided by Dr. Kendall Smith (Dartmouth Medical School, Hanover, NH). The anti-CD3 monoclonal antibodies used were OKT3 (Ortho Diagnostic Systems, Raritan, NJ) and Leu 4 (Becton-Dickinson \& Co., Mountain View, CA).

Assays for IL-1, IL-1 inhibitor, IL-2, and IL-2 receptors. The lymphocyte-activating factor assay (22) was used to measure IL-1 and IL-1 inhibitor activity in 24-h supernatants from cells that had been cultured at $2 \times 10^{6} / \mathrm{ml}$ in standard culture medium with and without mitogen. Thymocytes from 4-6-wk-old C3H/Hej mice were suspended in RPMI 1640 supplemented with $5 \%$ heat-inactivated fetal bovine serum, $5 \times 10^{-5}$ M 2-mercaptoethanol, $100 \mathrm{U} / \mathrm{ml}$ penicillin, $100 \mu \mathrm{g} / \mathrm{ml}$ streptomycin, 2 $\mathrm{mM}$ glutamine, and $12.5 \mu \mathrm{g} / \mathrm{ml}$ polymyxin B. Cells were cultured at $10^{6} /$ well in 96-well flat-bottom tissue culture plates in the presence of 1 $\mu \mathrm{g} / \mathrm{ml}$ PHA and a $25 \%$ final concentration of the peripheral blood mononuclear cell (PBMC) and synovial fluid mononuclear cell (SFMC) culture supernatants. Titration of these supernatants resulted in a dose-dependent loss of IL-1 activity. Thymocyte proliferation was measured by $\left[{ }^{3} \mathrm{H}\right]$ thymidine incorporation after $48 \mathrm{~h}$. To test for specificity of the activity, replicates of the supernatants were preincubated for $2 \mathrm{~h}$ at $37^{\circ} \mathrm{C}$ with a 1:100 dilution of antibody against human IL-1 (18) and then tested for residual IL-1 activity. In these studies, neutralization was accomplished by mixing culture supernates with a 1:100 dilution of antibody for $\sim 2 \mathrm{~h}$ at $37^{\circ} \mathrm{C}$ and then added these to murine thymocytes. Supernatants to be tested for IL-1 inhibitor activity were titrated against $10 \mathrm{U}$ of purified IL-1.

IL-2 was assayed after $48 \mathrm{~h}$ on the IL-2-dependent murine cell line CTLL-2 (20). Specificity assays were performed by neutralization $(2 \mathrm{~h}$, $\left.37^{\circ} \mathrm{C}\right)$ with anti-IL-1 antiserum (1:100) and anti-IL-2 monoclonal an- tibody (1:10), respectively. All supernatant samples were tested at a 1:4 final dilution which was determined to be an optimal endpoint by titration curves. IL-2 receptors were detected after incubation of extensively washed cells with a fluorescein-conjugated anti-IL-2 receptor monoclonal antibody (Becton, Dickinson \& Co., Sunnyvale, CA), followed by cytofluorographic analysis with a FACS IV (Becton, Dickinson \& Co.) as previously described (23).

Data analysis. All cultures were performed at least three times, each in triplicate. Mean values were compared by Student's $t$ test (two tails).

\section{Results}

Proliferative responses and lymphokine production in cultures of $R A$ and normal PBMC after stimulation with antibody OKT3. Optimal concentrations of antibody OKT3 $(1 \mathrm{ng} / \mathrm{ml})$ induced vigorous proliferation of PBMC from normal subjects and RA patients. The ranges of $\left[{ }^{3} \mathrm{H}\right]$ thymidine uptake in the normal group (26,382-112,123 cpm) and in the RA group (13,638$121,453 \mathrm{cpm}$ ) overlapped. The mean values of cultures with normal lymphocytes $(70,212 \pm 30,470)$ were not significantly different from those of RA lymphocytes $(45,616 \pm 64,378 \mathrm{cpm})$. Cultures from several RA patients, however, showed mean values considerably below those from normal patients. This group of patients had more active disease as characterized by erythrocyte sedimentation rate, rheumatoid factor titer, and joint counts.

In contrast, with suboptimal doses of OKT3, proliferation of lymphocytes from nearly all RA patients was depressed (Table II). Thus, using $0.1 \mathrm{ng}$ of OKT 3 , the $\left[{ }^{3} \mathrm{H}\right]$ thymidine uptake was $8,415 \pm 1,036$ for the RA patients compared with $35,175 \pm 2,432$ for the normal subjects $(P<0.01)$. Stimulation of RA and normal lymphocytes with $0.01 \mathrm{ng}$ of OKT 3 yielded a similarly significant difference. 
Table II. Proliferation and Interleukin Production after Stimulation with OKT3

\begin{tabular}{|c|c|c|c|c|c|c|c|c|}
\hline \multirow{2}{*}{$\begin{array}{l}\text { OKT3 } \\
\text { (ng/ml) }\end{array}$} & \multicolumn{2}{|l|}{0} & \multicolumn{2}{|l|}{0.01} & \multicolumn{2}{|l|}{0.1} & \multicolumn{2}{|l|}{1.0} \\
\hline & NL & RA & NL & RA & NL & RA & NL & RA \\
\hline & cpm & $c p m$ & cpm & cpm & cpm & cpm & cpm & $c p m$ \\
\hline Prolif. & $716 \pm 208$ & $193 \pm 94$ & $2,179 \pm 320$ & $500 \pm 182$ & $35,175 \pm 2,432$ & $8,415 \pm 1,036$ & $76,098 \pm 5,296$ & $59,966 \pm 4,944$ \\
\hline IL-2 & $2,682 \pm 312$ & $1,034 \pm 344$ & $4,322 \pm 538$ & $1,628 \pm 304$ & $28,744 \pm 1,898$ & $7,364 \pm 1,282$ & $42,836 \pm 3,994$ & $30,428 \pm 3,486$ \\
\hline IL-1 & $1,562 \pm 296$ & $986 \pm 282$ & $20,324 \pm 1,832$ & $1,426 \pm 256$ & $32,682 \pm 2,218$ & $3,426 \pm 752$ & $26,240 \pm 2,456$ & $15,312 \pm 1,746$ \\
\hline
\end{tabular}

PBMC from RA patients $(n=6)$ and normal subjects (NL) $(n=6)$ were stimulated with $0.01-1 \mathrm{ng} / \mathrm{ml}$ OKT3. Proliferation was assayed by $\left[{ }^{3} \mathrm{H}\right]$ thymidine uptake after $72 \mathrm{~h}$. IL-1 activity was measured on mouse thymocytes (assay background 1,326 cpm) and IL-2 activity on CTLL-2 cells (assay background 1,834 cpm) after $36 \mathrm{~h}$. Each culture was performed in triplicate. Each point represents the mean counts per minute \pm SEM of six experiments in the various assays.

The levels of IL-1 and IL-2 activities in the OKT3-stimulated cultures correlated well with the proliferative responses (Table II). Again, lymphocytes from RA patients and normal subjects released markedly different amounts of the two lymphokines after stimulation with 0.1 and $0.01 \mathrm{ng} / \mathrm{ml} \mathrm{OKT3}$ antibody.

Decreased proliferative responses in synovial fluid lymphocytes. Mononuclear cells from RA synovial fluids (SFMC) responded very weakly to OKT3 as compared with autologous PBMC $(P<0.001 ;$ Fig. 1$)$. The low response occurred throughout a wide dose range (Table III). The spontaneous proliferation (no added OKT3) of synovial fluid cells $(1,592 \pm 1,188 \mathrm{cpm})$ was not significantly $(P>0.05)$ different from that of peripheral blood lymphocytes $(1,136 \pm 946 \mathrm{cpm})$. Cell viability as estimated by trypan blue exclusion exceeded $90 \%$ in both SFMC and PBMC after $3 \mathrm{~d}$ in culture. Such variables as disease duration, disease activity, or medications did not appear to account specifically for the SFMC-impaired proliferation (cf. Table I).

To exclude the possibility that the low response of SFMC was related to the particular IgG subclass of the anti-CD3 antibody used, we compared the effects of two anti-CD3 antibodies, Leu $4\left(\operatorname{IgG}_{1}\right)$ and OKT3 $\left(\operatorname{IgG}_{2 \mathrm{a}}\right)$. The proliferative responses of RA SFMC were severely depressed (Fig. 1) with both antibodies. The Leu 4 monoclonal antibody will not activate the PBMC from $\sim 40 \%$ of normal donors $(10,12,24)$. The frequency of

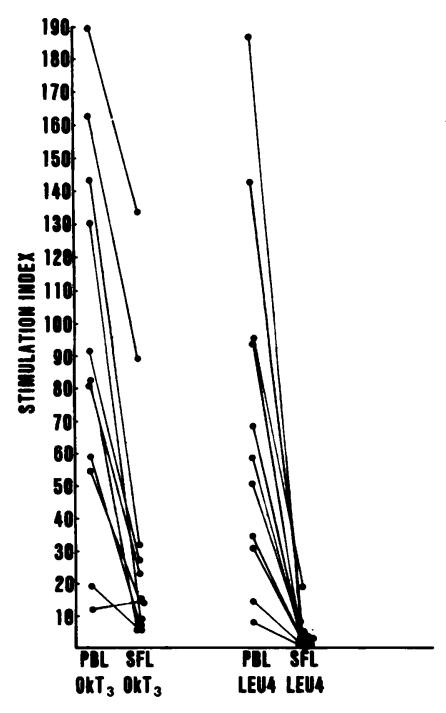

Figure 1. Proliferative responses of paired PBMC and SFMC samples from RA patients to stimulation with OKT3 $(1 \mathrm{ng} /$ $\mathrm{ml})$ and Leu $4(200 \mathrm{ng} / \mathrm{ml})$. Data are shown as mean stimulation index of $\left[{ }^{3} \mathrm{H}\right]$ thymidine uptake after $72 \mathrm{~h}$.
Leu 4 nonresponders did not differ among RA subjects (45\%); the data in Fig. 1 for RA were derived from responders.

We tested the possibility that the low response in SFMC could have been due to lower numbers of $T$ lymphocytes or to modulation of the T3 molecule. The relative proportions of OKT3, or of Leu 4-reactive $\mathrm{T}$ cells, to the total numbers of PBMC or SFMC were similar. In addition, FACS analysis revealed that the density of surface molecules reactive with the OKT3 and Leu 4 antibodies was indistinguishable in SFMC and PBMC (data not shown).

Effects of indomethacin and of preincubation on OKT3-induced proliferation. Activated cells in synovial fluid may release prostaglandins which can inhibit lymphocyte responses, particularly the secretion of IL-2 (25). To evaluate whether prostaglandins were involved in the low proliferative responses observed, OKT3-stimulated PBMC and SFMC were cultured with indomethacin $(1-10 \mu \mathrm{g} / \mathrm{ml})$, an inhibitor of prostaglandin synthesis. Under these conditions proliferation of PBMC was augmented by only $34 \%$ and that of synovial cells by $28 \%$ (data not shown). The difference between the responses of cells from synovial fluid and blood remained significant.

Cells in the synovial fluid are exposed in vivo to immunoglobulin aggregates, which may block Fc receptors on monocytes and thereby prevent OKT3 mitogenesis (26). Therefore, we preincubated SFMC for 24,48 , and $74 \mathrm{~h}$ in medium alone before the addition of OKT3 in order to permit shedding of immunoglobulins and clearing of Fc receptors. The preincubation did not alter the low proliferative response of SFMC (data not shown).

Production of interleukins by OKT3-stimulated PBMC and SFMC. Supernatants of PBMC and SFMC cultures stimulated with OKT3 $(1 \mathrm{ng} / \mathrm{ml})$ were harvested after 24 and $48 \mathrm{~h}$ and assayed for IL-1 and IL-2 activities, respectively. The interleukin results corresponded remarkably with the proliferative responses (Figs. 2 and 3). IL-1 and IL-2 activities were markedly lower in SFMC culture supernatants as compared with PBMC. The supernatants of SFMC did not have toxicity for the cells used in the bioassays. They impaired neither the proliferation of mouse thymocytes stimulated with $10 \mu \mathrm{g} / \mathrm{ml}$ PHA, nor the proliferative responses of CTLL-2 to recombinant human or rat IL-2 (results not shown).

Exogenous purified IL-1 at $32 \mathrm{U} / \mathrm{ml}$ caused a threefold increase in OKT3-induced IL-2 secretion from SFMC. Under these conditions, therefore, IL-2 levels in SFMC and PBMC super- 
Table III. Proliferative Responses of SFMC to OKT3 Stimulation

\begin{tabular}{llllll}
\hline OKT3 $(\mathrm{ng} / \mathrm{ml})$ & & & & & \\
\hline 0 & 0.001 & 0.01 & 0.1 & 1 & 10 \\
\hline$c p m$ & $c p m$ & $c p m$ & $c p m$ & $c p m$ & $c p m$ \\
$1,592 \pm 632$ & $1,786 \pm 582$ & $2,268 \pm 540$ & $3,424 \pm 636$ & $9,582 \pm 1,210$ & $15,450 \pm 1,352$ \\
\hline
\end{tabular}

SFMC were stimulated with varying doses of OKT3 $(0-10 \mathrm{ng} / \mathrm{ml})$. Proliferation was quantified after $72 \mathrm{~h}$ as [3H]thymidine uptake. Data are shown as mean counts per minute $\pm \mathrm{SEM}$ of six experiments.

natants became much more similar. In each case, the IL-2 activity could be neutralized with the anti-IL-2 antibody (Fig. 3). The rising baseline of unneutralized counts per minute was possibly attributable to unknown contaminants in the IL-1 preparation used.

IL-2 receptor expression and modulation by interleukins. SFMC and PBMC were stained when freshly isolated, or were cultured with OKT3 $(1 \mathrm{ng} / \mathrm{ml})$ or with medium alone for $48 \mathrm{~h}$. Table IV shows the data for the cultured cells. The freshly isolated cells stained similarly. A high proportion of SFMC (19.4 $4.6 \%)$ expressed IL-2 receptors prior to anti-CD3 stimulation, whereas only a small portion of PBMC from either normal or RA donors cultured in medium alone were positive. After stimulation with OKT3, the proportion of IL-2 receptor positive cells increased to $45.6 \pm 5.2 \%$ in RA PBMC and to $47.3 \pm 62 \%$ in normal PBMC, but only to $22.6 \%$ in SFMC.

We then tested whether addition of exogenous interleukins would improve the proliferative responses and increase IL-2 receptor expression. The effects of recombinant human IL-2 at $7.5-30 \mathrm{U} / \mathrm{ml}$ and of purified IL-1 at $8-32 \mathrm{U} / \mathrm{ml}$ are shown in Table IV and Fig. 4. The addition of neither IL-1 nor IL-2 increased significantly the number of IL-2 receptor-positive cells in the PBMC, and affected minimally or not at all the responses to OKT3. Consistent with this, the lymphokines had only modest effects on the proliferative responses of the PBMC (Fig. 4). In SFMC cultures, however, the lymphokine additions had a much more substantial effect (Fig. 4 and Table III). The addition of IL-2 alone induced modest proliferation of SFMC in the absence of OKT3 (Fig. $4 \mathrm{~B}$ ). This is consistent with the intrinsic expression of IL-2 receptors on these cells (Table IV) and demonstrates that the receptors are functional. Both IL-1 and IL-2 promoted

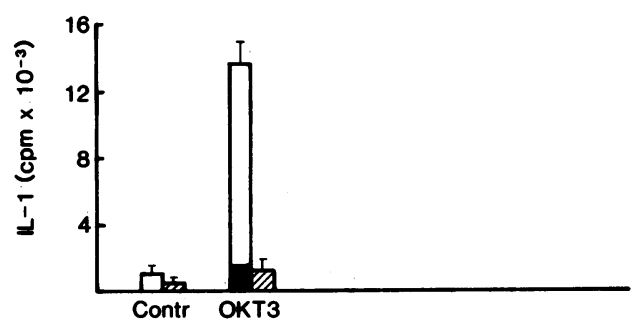

Figure 2. IL-1 activity in culture supernatants collected after $24 \mathrm{~h}$ from unstimulated (Contr) and OKT3 $(1 \mathrm{ng} / \mathrm{ml})$ stimulated PBMC (open bars) and SFMC (hatched bars) of RA patients. IL-1 activity was assayed on mouse thymocytes. Data are shown as mean counts per minute \pm SEM. Background $\left[{ }^{3} \mathrm{H}\right]$ thymidine uptake of thymocytes was $1,422 \pm 294 \mathrm{cpm}$. The inserted solid bar indicates residual proliferative activity after preincubation of the supernatant with anti-IL-1 antibody. increased responses of the SFMC to OKT3 $(1 \mathrm{ng} / \mathrm{ml})$. With both, the increase was dose-dependent. At $30 \mathrm{U} / \mathrm{ml}$ of IL-2, the OKT3induced proliferation of SFMC was close to that of PBMC (Fig. $4 B$ ). Purified IL-1 by itself did not trigger significant levels of proliferation.

$I L-1$ inhibitor in culture supernatants from $R A P B M C$ and $S F M C$. Supernatants from RA PBMC and SFMC cultured with or without OKT3 were tested for neutralization of a standard IL-1 preparation. Fig. 5 shows that supernatants from both types of cells contained a factor that neutralizes IL-1. However; much higher concentrations of the IL-1 inhibitor were detected in SFMC cultures. The inhibitor activity decreased after OKT3 stimulation, but still persisted in high titer in SFMC cultures (Fig. 5). It was not detectable in supernatants of normal PBMC cultures. Culture supernatants from RA SFMC did not neutralize the effect of purified or recombinant human IL-2 on CTLL-2 cells (Table V). Furthermore, $\left[{ }^{3} \mathrm{H}\right]$ thymidine uptake by mouse thymocytes stimulated with optimal doses of PHA was not reduced by RA SFMC culture supernatants (data not shown), excluding nonspecific inhibition of thymocyte proliferation. The IL-1 inhibitor was nondialyzable, and therefore it could not be a smaller molecule such as a prostaglandin. In support of this conclusion, supernatants from cells cultured with indomethacin retained IL-1 inhibitory activity (not shown). More important, SFMC supernatants containing IL-1 inhibitory activity decreased OKT3-induced proliferation of normal PBMC (Table VI). The inhibition could be overcome by adding exogenous IL-1.

To determine the cellular source of the IL-1 inhibitor activity

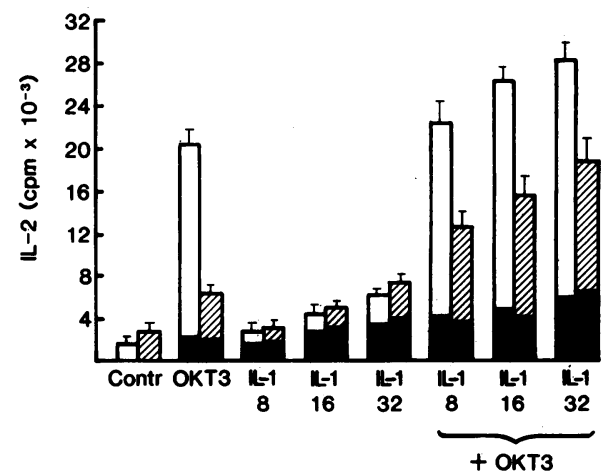

Figure 3. IL-2 activities in culture supernatants of RA PBMC (open bars) and SFMC (hatched bars). The addition of increasing amounts of purified IL-1 to a standard dose of OKT3 $(1 \mathrm{ng} / \mathrm{ml})$ increased progressively the responses of the SFMC to the OKT3. Inserted solid bars indicate residual proliferative activity after preincubation of the supernatant with anti-IL-2 antibody. IL-2 was assayed after $48 \mathrm{~h}$ of incubation on CTLL- 2 cells. 
Table IV. IL-2 Receptor Expression

\begin{tabular}{lcrrl}
\hline & & NL PBMC & RA PBMC & \multicolumn{1}{l}{ RA SFMC } \\
\hline & & \multicolumn{1}{l}{$\%$} & \multicolumn{1}{l}{$\%$} \\
Control & & & \multicolumn{1}{l}{$\%$} & \\
OKT3 & & $47.3 \pm 6.2$ & $45.6 \pm 5.2$ & $22.6 \pm 3.9$ \\
IL-1 & 8 & $2.3 \pm 1.4$ & $2.6 \pm 1.2$ & $17.2 \pm 3.4$ \\
& 16 & $2.8 \pm 2.2$ & $3.2 \pm 1.6$ & $21.3 \pm 2.8$ \\
& 32 & $3.2 \pm 2.1$ & $2.8 \pm 1.2$ & $18.4 \pm 3.0$ \\
OKT3+IL-1 & 8 & $49.7 \pm 5.2$ & $51.2 \pm 4.9$ & $34.2 \pm 2.9$ \\
& 16 & $52.0 \pm 6.7$ & $52.4 \pm 5.2$ & $36.4 \pm 3.2$ \\
& 32 & $57.3 \pm 5.4$ & $50.2 \pm 4.6$ & $39.7 \pm 3.6$ \\
IL-2 & 7.5 & $3.2 \pm 1.4$ & $2.6 \pm 1.8$ & $21.3 \pm 3.4$ \\
& 15 & $2.8 \pm 1.2$ & $2.9 \pm 1.2$ & $17.6 \pm 2.8$ \\
& 30 & $2.5 \pm 1.6$ & $1.8 \pm 1.2$ & $15.4 \pm 3.2$ \\
OKT3+IL-2 & 7.5 & $51.2 \pm 4.9$ & $52.6 \pm 4.8$ & $35.4 \pm 3.6$ \\
& 15 & $54.4 \pm 5.3$ & $56.4 \pm 5.2$ & $38.2 \pm 4.2$ \\
& 30 & $56.2 \pm 6.4$ & $55.3 \pm 4.6$ & $42.8 \pm 3.9$ \\
& & & & \\
\hline
\end{tabular}

Mononuclear cells from normal donors (NL) and paired samples of RA peripheral blood and synovial fluid were cultured in medium alone, in the presence of OKT3 $(1 \mathrm{ng} / \mathrm{ml})$ alone, or in the presence of varying concentrations $(\mathrm{U} / \mathrm{ml})$ of $\mathrm{IL}-1$ or IL-2 with and without OKT3. Cells were harvested after $48 \mathrm{~h}$, stained with fluorescein-conjugated anti-IL-2 receptor monoclonal antibody and analyzed in the FACS. Data are shown as percent IL-2 receptor-positive cells \pm SEM of seven experiments.

we depleted SFMC of monocytes by plastic adherence and subsequent carbonyl-iron treatment. The adherent cells were dislodged from the plastic surfaces with EDTA and cultured in parallel with SFMC and monocyte-depleted SFMC. Table VII shows that the IL-1 inhibitor activity is predominantly derived from the monocyte-enriched population.

In an attempt to dissociate IL-1 from the IL-1 inhibitor(s), SFMC culture supernatants were chromatographed on phosphocellulose columns. After elution with a linear salt gradient (0.1-1 M), fractions were dialyzed against RPMI and tested on mouse thymocytes for IL-1 activity. The IL-1 activity eluted as a single peak at $0.3 \mathrm{M} \mathrm{NaCl}$ (Fig. 6) and was neutralized with the anti-IL-1 antibody. The IL-1 inhibitory activity did not bind to phosphocellulose and eluted with the void volume of the column (Fig. 6). Thus, SFMC supernatants do contain biologically active IL-1, which can be detected after separation from the IL-1 inhibitor(s).

Mixing of lymphocytes and monocytes from blood and synovial fluid. Having demonstrated that synovial fluid monocytes release much higher levels of IL-1 inhibitor activity than blood monocytes, we tested various combinations of purified lymphocytes and monocytes. PBMC and SFMC from the same patient were partially depleted of monocytes by plastic adherence. Residual monocytes were removed by carbonyl-iron treatment. The adherent cells were dislodged with trypsin-EDTA and recombined with lymphocytes. Table VIII shows that both monocytedepleted PBMC and SFMC, as expected, did not respond to OKT3. When recombined with $10 \%$ blood monocytes, blood lymphocytes (two of three experiments) gave a high proliferative response, but with monocytes from synovial fluid, they uniformly
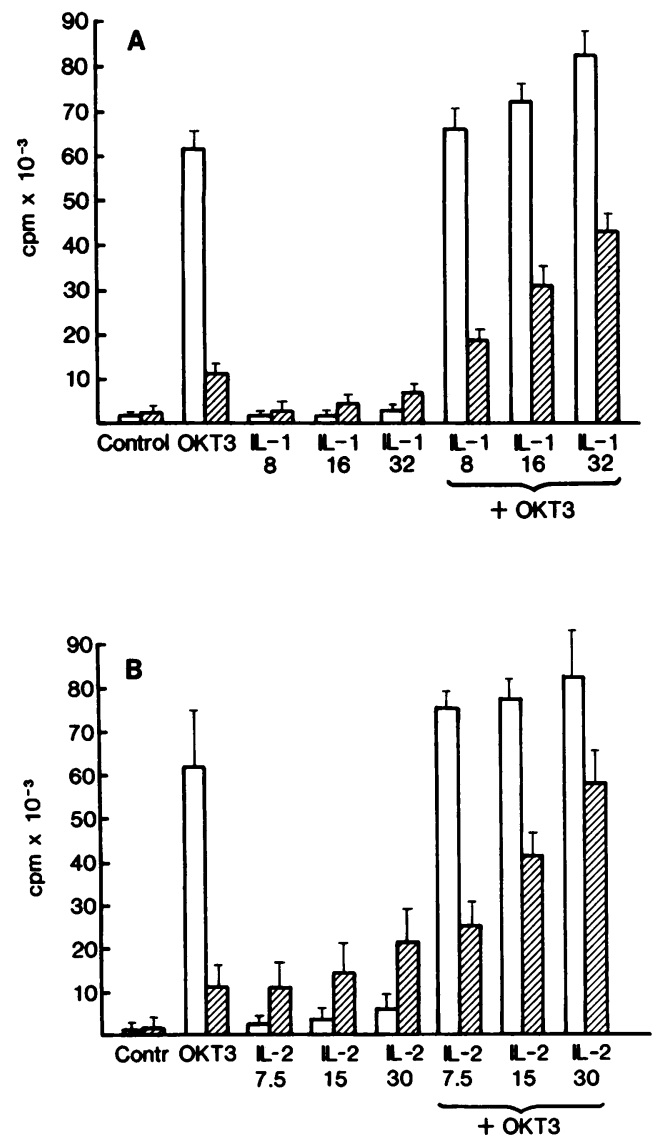

Figure 4. Proliferative responses of RA PBMC (open bars) and SFMC (hatched bars) in response to OKT3 $(1 \mathrm{ng} / \mathrm{ml})$ in the presence of exogenous IL-1 (8-32 U/ml) $(B)$ or IL-2 (7.5-30 U/ml) $(A)$. Proliferation was measured as $\left[{ }^{3} \mathrm{H}\right]$ thymidine incorporation after $72 \mathrm{~h}$. Data are shown as mean counts per minute \pm SEM.

showed low responses. With synovial fluid monocytes, synovial fluid lymphocytes gave a characteristically low proliferative response, but with blood monocytes they gave much higher responses. These results thus demonstrate that the poor mitogen

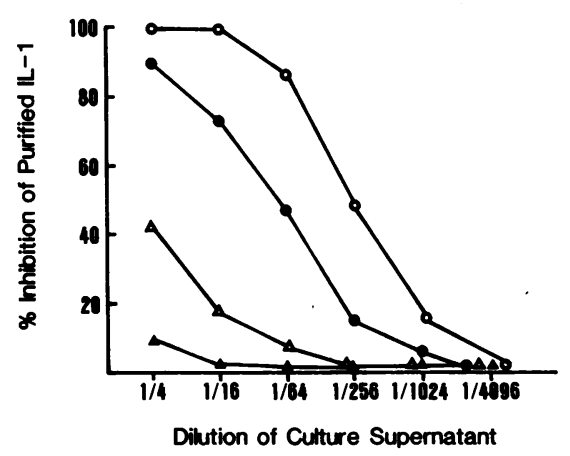

Figure 5. Inhibition of purified IL-1 activity by supernatants from RA PBMC (triangles) and SFMC (circles). Open symbols represent supernatants from unstimulated cultures and closed symbols represent supernatants from OKT3 $(1 \mathrm{ng} / \mathrm{ml})$-stimulated cultures. Various dilutions of culture supernatants were mixed with $10 \mathrm{U} / \mathrm{ml}$ of purified IL1 , incubated for $2 \mathrm{~h}$ at $37^{\circ} \mathrm{C}$, and then assayed on mouse thymocytes. Results are expressed as percent inhibition of the activity of $10 \mathrm{U} / \mathrm{ml}$ IL-1 on mouse thymocytes. 
Table V. RA Culture Supernatants Inhibit IL-1, but not IL-2 Activity

\begin{tabular}{|c|c|c|c|c|c|c|c|}
\hline & \multirow[b]{2}{*}{ No supernatant } & \multicolumn{6}{|c|}{ Dilution of RA culture supernatant } \\
\hline & & $1 / 4$ & $1 / 16$ & $1 / 64$ & $1 / 206$ & $1 / 1,024$ & $1 / 4,096$ \\
\hline & $c p m$ & $c p m$ & $c p m$ & $c p m$ & $c p m$ & $c p m$ & $c p m$ \\
\hline IL-1 & $16,384 \pm 1,592$ & $1,386 \pm 283$ & $1,945 \pm 342$ & $2,468 \pm 382$ & $7,452 \pm 688$ & $15,384 \pm 1,293$ & $17,450 \pm 1,582$ \\
\hline IL-2 & $24,586 \pm 2,134$ & $18,934 \pm 1,731$ & $22,834 \pm 1,926$ & $26,879 \pm 2,031$ & $23,452 \pm 2,186$ & $23,987 \pm 1,824$ & $26,872 \pm 2,398$ \\
\hline
\end{tabular}

Culture supernatants from RA SFMC were added to mouse thymocytes stimulated with $10 \mathrm{U} / \mathrm{ml} \mathrm{IL}-1$ and to CTLL-2 cells stimulated with 7.5 $\mathrm{U} / \mathrm{ml}$ IL-2. Data shown are mean counts per minute \pm SEM of triplicates from four experiments.

Table VI. Inhibition of Proliferation in Normal PBMC by RA SFMC Supernatants Can Be Overcome by IL-1

\begin{tabular}{|c|c|c|c|c|c|}
\hline \multirow{2}{*}{$\begin{array}{l}\text { Percent (vol/vol) } \\
\text { of RA supernate }\end{array}$} & \multirow[b]{2}{*}{ Control } & \multicolumn{4}{|l|}{$\begin{array}{l}\text { OKT3 } \\
\text { IL-1 (U/ml) }\end{array}$} \\
\hline & & 0 & 8 & 16 & 32 \\
\hline & $c p m$ & $c p m$ & $c p m$ & $c p m$ & $c p m$ \\
\hline 0 & $1,438 \pm 312$ & $72,684 \pm 5,344$ & $74,862 \pm 6,212$ & $71,454 \pm 5,846$ & $74,934 \pm 6,032$ \\
\hline 25 & $1,234 \pm 286$ & $6,322 \pm 844$ & $9,424 \pm 1,028$ & $21,436 \pm 1,936$ & $38,492 \pm 2,836$ \\
\hline 6.2 & $1,380 \pm 344$ & $19,256 \pm 1,636$ & $31,242 \pm 2,934$ & $53,830 \pm 4,286$ & $70,338 \pm 5,432$ \\
\hline 1.6 & $1,552 \pm 368$ & $38,294 \pm 3,228$ & $44,826 \pm 3,892$ & $56,394 \pm 4,342$ & $68,394 \pm 4,874$ \\
\hline 0.4 & $1,636 \pm 402$ & $59,462 \pm 4,944$ & $64,334 \pm 5,386$ & $72,580 \pm 6,244$ & $79,334 \pm 6,232$ \\
\hline
\end{tabular}

PBMC from normal donors were cultured in medium alone, or were stimulated with OKT3 $(1 \mathrm{ng} / \mathrm{ml})$ with simultaneous addition of 0.4-25\% of RA SFMC culture supernatants and/or 8-32 U/ml of purified IL-1. Proliferation was assessed by [ ${ }^{3} \mathrm{H}$ ] thymidine incorporated after $72 \mathrm{~h}$. Data are shown as mean counts per minute \pm SEM of two experiments.

Table VII. Cellular Origin of IL-1 Inhibitor in SFMC

\begin{tabular}{|c|c|c|c|c|c|c|}
\hline & \multicolumn{6}{|c|}{ Dilution of culture supernatant } \\
\hline & $1 / 4$ & $1 / 16$ & $1 / 64$ & $1 / 216$ & $1 / 1,024$ & $1 / 4,096$ \\
\hline & $c p m$ & $c p m$ & $c p m$ & $c p m$ & $c p m$ & $c p m$ \\
\hline SFMC & $1,068 \pm 264$ & $1,820 \pm 318$ & $3,644 \pm 428$ & $8,937 \pm 756$ & $15,438 \pm 1,036$ & $17,994 \pm 1,628$ \\
\hline $\mathbf{M} \phi^{-}$ & $16,386 \pm 1,384$ & $18,243 \pm 2,044$ & $17,483 \pm 1,686$ & $20,344 \pm 1,932$ & $19,328 \pm 1,757$ & $19,892 \pm 1,863$ \\
\hline $\mathbf{M} \phi^{+}$ & $1,216 \pm 304$ & $1,436 \pm 296$ & $2,038 \pm 343$ & $5,489 \pm 492$ & $11,398 \pm 946$ & $18,368 \pm 1,456$ \\
\hline
\end{tabular}

SFMC, monocyte-depleted SFMC $\left(\mathrm{M}^{-}, 2 \times 10^{6} / \mathrm{ml}\right)$, and monocytes isolated by adherence from SFMC $\left(\mathrm{M}^{+}, 2 \times 10^{5} / \mathrm{ml}\right)$ were cultured for 48 $h$ and supernatants were tested for IL-1-inhibitor activity against $10 \mathrm{U}$ of a standard IL-1 preparation which gave $18,324 \pm 1,626 \mathrm{cpm}$ in the mouse thymocyte assay over a background of $1,268 \pm 242 \mathrm{cpm}$. Data are shown as mean counts per minute $\pm \mathrm{SEM}$ of $\left[{ }^{3} \mathrm{H}\right]$ thymidine incorporation after $48 \mathrm{~h}$.

response in SFMC is predominantly a monocyte function. Furthermore, a simple numerical difference in monocytes does not appear to account for the poor mitogen response in SFMC.

\section{Discussion}

The present investigation has analyzed the basis for the defective mitogen responses of RA SFMC with anti-CD3 antibodies. In nearly all cases, the OKT3-induced proliferation of SFMC was depressed severely and indeed was significantly lower than that of PBMC in paired samples. To analyze the hyporesponsiveness of SFMC, the sequence of activation events leading to $T$ cell mitogenesis with anti-CD3 antibodies was dissected. OKT3- stimulated SFMC released minimal IL-1 and IL-2 activity. The addition of purified IL-1 to OKT3-stimulated SFMC markedly increased IL-2 secretion, suggesting that the lack of IL-2 was the consequence of deficient IL-1. IL-2 receptors were expressed on a large proportion of SFMC without prior in vitro stimulation, consistent with their activated state (27-30). The addition of recombinant IL-2 to SFMC triggered modest proliferation demonstrating that the IL-2 receptors were functional. Little increase in IL-2 receptors occurred after stimulation of SFMC with OKT3 alone. Only the simultaneous addition of either IL-1 or IL-2 together with OKT3 induced a major increase in IL-2 receptors in SFMC; both also increased proliferation. The recent finding that purified IL-1 induces IL-2 receptor expression in PBMC 


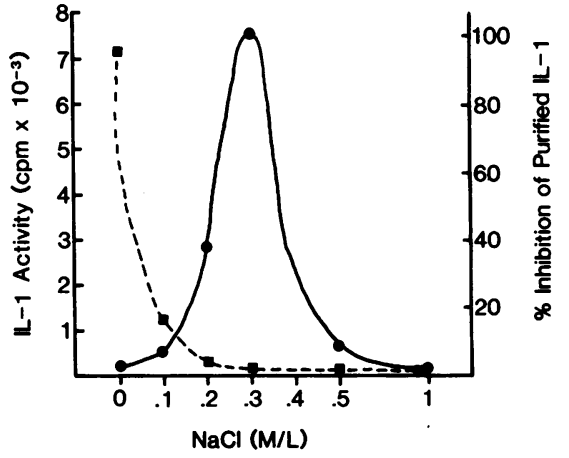

Figure 6. Fractionation of SFMC culture supernatants on phosphocellulose column. Supernatants were loaded in $20 \mathrm{mM}$ Tris- $\mathrm{HCl}$ pH 7.4. The column was then eluted with various stepwise concentrations of $\mathrm{NaCl}$. The fractions were dialyzed and then tested for IL-1 (O) and IL-1 inhibitory ( $\square$ ) activities.

incubated with immobilized anti-T3 antibody (64.1) is in accord with these results (13).

In control experiments with PBMC, IL-2 receptor expression and/or proliferation increased very little after addition of exogenous IL-1 or IL-2, although they did significantly so with SFMC. Mixing experiments with purified monocytes and lymphocytes from blood and synovial fluid showed that synovial fluid lymphocytes gave a much higher proliferative response in the presence of autologous blood monocytes. Conversely, blood lymphocytes gave a low response in the presence of autologous synovial monocytes. In other experiments, synovial fluid monocytes were shown to be a rich source and blood monocytes a weak source of an IL-1 inhibitor. Collectively, these results strongly suggest that the defective proliferative and IL-2 secretory responses of OKT3-stimulated SFMC from RA patients are largely attributable to a deficiency in functional IL-1 activity.

The importance of IL-1 in anti-CD3 mitogenesis is demonstrated by several experiments that will be reported separately (Lotz, M., J. Bentin, and C. D. Tsoukas, unpublished data). Thus, the addition of antibody against IL-1 to OKT3 stimulated normal PBMC reduces the proliferative response. Furthermore, IL-1 is not detectable in Leu 4-stimulated PBMC of Leu 4 nonresponders. Finally, soluble OKT3 did not induce IL-1 from isolated monocytes, but did so when both monocytes and $\mathrm{T}$ cells were present, indicating that IL-1 release after OKT3 is the result of a monocyte- $T$ cell interaction and not due simply to a contaminant in the antibody preparation.

We were able to explain the low IL-1 activity in RA cultures on the basis of a specific IL- 1 inhibitor. The IL-1 inhibitor was detected in large quantities in SFMC cultures. Its action was selective for IL-1, in that it neutralized neither purified nor recombinant human IL-2. The inhibitor(s) was not a prostaglandin, nor were prostaglandins apparently involved in its induction. The inhibitor was not nonspecifically toxic to mouse thymocytes. SFMC culture supernatants with IL-1 inhibitory activity decreased OKT3-induced proliferation of normal PBMC. This effect was overcome by purified exogenous IL-1.

Fractionation of SFMC culture supernatants on phosphocellulose allowed separation of biologically active IL-1 from the IL-1 inhibitor. Several factors that neutralize IL-1 have been described. Epstein-Barr virus-transformed B cell lines released a 95-kD protein that blocks IL-1 effects on mature T lymphocytes and thymocytes (31). We have also seen an IL-1 inhibitor in the supernatants of RA PBMC infected in vitro with Epstein-Barr virus (32). During endotoxin fever, human serum contains a factor that inhibits IL-1 effects on mouse thymocytes (33). Furthermore, in the urine of febrile patients a $20-40-\mathrm{kD}$ glycoprotein was identified which specifically blocks IL-1-induced thymocyte proliferation (34). Synovial fluid also contains a factor that masks IL-1 activity, but this has not been characterized (35). Arend et al. (36) induced the production of a $22-\mathrm{kD}$ IL-1 inhibitor by culturing human monocytes on adherent immune complexes or antibodies. Cytomegalovirus infection of monocytes and a monocytic cell line caused release of an IL-1-specific inhibitor (37). Thus, a variety of IL-1 inhibitors have been described in vivo and in vitro. To ascertain the biochemical and immunologic relationships of the different IL-1 inhibitors will require their purification, the preparation of monospecific antibodies to them, and characterization of their genetic sources.

Table VIII. Mixing of Lymphocytes and Monocytes from Blood and Synovial Fluid

\begin{tabular}{|c|c|c|c|c|c|c|c|c|}
\hline & PBMC & SFMC & $\mathbf{M} \phi^{-P B M C}$ & $\mathbf{M} \phi^{-}$SFMC & $\begin{array}{l}\mathrm{M} \phi^{-} \mathrm{PBMC} \\
+10 \% \text { PBM } \phi\end{array}$ & $\begin{array}{l}\mathrm{M} \phi \text {-PBMC } \\
+10 \% \text { SFM } \phi\end{array}$ & $\begin{array}{l}\mathrm{M} \phi \text {-SFMC } \\
+10 \% \text { SFM } \phi\end{array}$ & $\begin{array}{l}\mathrm{M} \phi-\mathrm{SFMC} \\
+10 \% \text { PBM } \phi\end{array}$ \\
\hline & $\mathrm{cpm}$ & cpm & $c p m$ & cpm & cpm & $c p m$ & $c p m$ & $c p m$ \\
\hline \multicolumn{9}{|l|}{ Exp. 1} \\
\hline Contr. & 1,154 & 842 & 1,892 & 2,689 & 1,783 & 1,139 & 1,832 & 3,044 \\
\hline OKT3 & 50,384 & 6,843 & 2,684 & 3,246 & 44,892 & 8,364 & 9,024 & 42,822 \\
\hline \multicolumn{9}{|l|}{ Exp. 2} \\
\hline Contr. & 1,682 & 1,234 & 1,434 & 2,382 & 1,434 & 1,580 & 2,034 & 2,643 \\
\hline OKT3 & 66,493 & 10,493 & 2,281 & 2,883 & 57,983 & 14,394 & 11,386 & 36,587 \\
\hline \multicolumn{9}{|l|}{ Exp. 3} \\
\hline Contr. & 1,904 & 2,638 & 1,428 & 3,022 & 1,228 & 1,779 & 2,976 & 2,588 \\
\hline OKT3 & 83,685 & 13,892 & 1,139 & 2,756 & 5,364 & 6,824 & 4,582 & 52,893 \\
\hline
\end{tabular}

PBMC or SFMC from three RA patients were depleted of monocytes $\left(\mathrm{M}^{-}\right)$and recombined with $10 \%$ autologous monocytes from the same source or mixed in a crisscross manner. Proliferation was measured as $\left[{ }^{3} \mathrm{H}\right]$ thymidine uptake after $72 \mathrm{~h}$. Data are shown as mean counts per minute from triplicates. 
The prominent feature of the IL-1 inhibitors is that they appear regularly during inflammatory responses induced by diverse stimuli. Perhaps immune complexes or a viral agent represent the eventual stimulus for IL-1 inhibitor production in all cases. In this fashion, products of an inflammatory response may control $\mathrm{T}$ lymphocyte activation and lymphokine production via a normal feedback mechanism.

In RA patients, lymphocyte proliferation and lymphokine secretion in the synovial fluid may be dampened by the IL-1 inhibitor(s). However, it remains unclear whether this is a deleterious or beneficial phenomenon. Certainly the inhibitor(s) should impair $\mathrm{T}$ cell-mediated inflammatory responses. At the same time the resultant $T$ cell immunodeficiency might facilitate the persistence of inciting agents and release autoantibody-secreting B cells from regulatory control. An analysis of the effects of the IL-1 inhibitor(s) on T cell-regulated autoantibody responses, and on the immune response to environmental pathogens, warrants further detailed study.

We do not know whether there is anything specific about the IL-1 inhibitor for RA synovitis as compared with other synovitic disease. We do know, however, that the appearance of an IL-1 inhibitor in the supernatants of Epstein-Barr virus-infected PBMC is not limited to RA, but may occur in other autoimmune diseases, although not in normal controls (38).

\section{Acknowledgments}

We gratefully acknowledge the BCR Word Processing Center for preparing the manuscript for this article.

Funding for this research was provided in part by grants AM-21175, AM-07144, AM-25443, and RR00833 AI-15614 from the National Institutes of Health and grants from the Rheumatic Diseases Research Foundation, the Lilly Research Laboratories, and the Deutsche Forschungsgemeinschaft (Lo 3181/1).

\section{References}

1. Silverman, H. A., J. S. Johnson, J. H. Vaughan, and J. C. McGlamory. 1976. Altered lymphocyte reactivity in rheumatoid arthritis. Arthritis Rheum. 19:509-515.

2. Stratton, J. A., and J. B. Peter. 1978. The responses of peripheral blood and synovial lymphocytes of patients with rheumatoid arthritis to in vitro stimulation with mitogens. Clin. Immunol. Immunopathol. 10: 233-241.

3. Petersen, J., V. Andersen, T. Ingemann-Hansen, J. Halkjaer-Kristensen, A. Wiik, and H. Thyssen. 1983. Synovial fluid and blood monocyte influence on lymphocyte proliferation in rheumatoid arthritis and traumatic synovitis. Scand. J. Rheumatol. 12:299-304.

4. Henkart, P. A., and R. I. Fisher. 1975. Characterization of the lymphocyte surface receptors for ConA and PHA. J. Immunol. 114:710714.

5. Valentine, M. A., C. D. Tsoukas, G. Rhodes, J. H. Vaughan, and D. A. Carson. 1985. Phytohaemagglutinin binds to the 20 kilodalton molecule of the T3 complex. Eur. J. Immunol. 15:851-854.

6. O'Flynn, K., A. M. Krensky, P. C. L. Beverly, S. J. Burakoff, and D. C. Linch. 1985. Phytohaemagglutinin activation of T cells through the sheep red blood cell receptor. Nature (Lond.). 313:686-687.

7. Chang, T. W., P. C. Kung, S. P. Gingras, and G. Goldstein. 1981. Does OKT3 monoclonal antibody react with an antigen-recognition structure on human T cells? Proc. Natl. Acad. Sci. USA. 78:1805-1808.

8. Tsoukas, C. D., M. Valentine, M. Lotz, J. H. Vaughan, and D. A. Carson. 1984. The role of the T3 molecular complex in antigen recognition and subsequent activation events. Immunol. Today. 5:311313.

9. Van Wauwe, J. P., J. R. De Mey, and J. G. Goossens. 1980.
OKT3: a monoclonal anti-human $\mathrm{T}$ lymphocyte antibody with potent mitogenic properties. J. Immunol. 124:2708-2713.

10. Van Wauwe, J. P., and J. G. Goossens. 1983. The mitogenic activity of OKT3 and anti-Leu4 monoclonal antibodies: a comparative study. Cell. Immunol. 77:23-29.

11. Clement, L. T., A. B. Tilden, and N. E. Dunlap. 1985. Analysis of the monocyte $\mathrm{Fc}$ receptors and antibody-mediated cellular interactions required for the induction of $\mathrm{T}$ cell proliferation by anti-T3 antibodies. J. Immunol. 135:165-171.

12. Kaneoka, H., G. Perez-Rojas, T. Sasasuki, C. Benike, and E. G. Engleman. 1984. Human T lymphocyte proliferation induced by a panT monoclonal antibody (anti-Leu4): heterogeneity of response is a function of monocytes. J. Immunol. 13:158-164.

13. Williams, J. M., D. De Loria, J. A. Hansen, C. A. Dinarello, R. Loentscher, H. M. Shapiro, and T. B. Strom. 1985. The events of primary T-cell activation can be staged by use of Sepharose bound anti-T3 (64.1) monoclonal antibody and purified interleukin-1. J. Immunol. 135:22492255.

14. Schwab, R., M. Y. Crow, C. Russo, and M. E. Weksler. 1985. Requirements for T cell activation by OKT3 monoclonal antibody: Role of modulation of T3 molecules and interleukin 1. J. Immunol. 135: 1714-1718.

15. Ropes, M. W., G. A. Bennet, and S. Cobb. 1958. Revision of diagnostic criteria for rheumatoid arthritis. Bull. Rheum. Dis. 9:175176.

16. Boyum, A. 1968. Isolation of mononuclear cells and granulocytes from human blood. Scand. J. Lab. Invest. 21:77-80.

17. Auron, P. E., A. C. Webb, L. J. Rosenwasser, S. F. Mucci, A. Rich, S. M. Wolff, and C. A. Dinarello. 1984. Nucleotide sequence of human monocyte interleukin-1 precursor cDNA. Proc. Natl. Acad. Sci. USA. 81:7907-7911.

18. Dinarello, C. A., L. Renfer, and S. M. Wolff. 1977. Human leukocytic pyrogen: purification and development of radioimmunoassay. Proc. Natl. Acad. Sci. USA. 74:4624-4627.

19. Wang, A., S. D. Lu, and D. F. Mark. 1984. Site specific mutagenesis of the human interleukin-2 gene: structure-function analysis of the cystein residue. Science (Wash. DC). 224:1431-1433.

20. Gillis, S., and J. Watson. 1980. Biochemical and biological characterization of lymphocyte regulatory molecules. V. Identification of an interleukin-2 producing human leukemia T cell line. J. Exp. Med. 152: 1709-1719.

21. Smith, K. A., M. F. Favata, and S. Oroszlan. 1983. Production and characterization of monoclonal antibodies to human interleukin: strategy and tactics. J. Immunol. 131:1808-1815.

22. Gery, I., R. K. Gershon, and B. H. Waksman. 1972. Potentiation of the T lymphocyte response to mitogens. The responding cell. J. Exp. Med. 136:128-142.

23. Julius, M. D., R. G. Sweet, C. G. Fathman, and L. A. Herzenberg. 1974. Fluorescence activated cell sorting and its applications. In Mammalian Cells: Probes and Problems. Proceedings of the First Los Alamos Life Science Symposium AEC Series (CONS: 73-1007). 107.

24. Tax, W. J. M., H. W. Willems, P. P. M. Reekers, P. J. A. Capel, and R. A. P. Koene. 1983. Polymorphism in mitogenic effect of IgG1 monoclonal antibodies against T3 antigen on human $\mathrm{T}$ cells. Nature (Lond.). 304:445-447.

25. Tilden, A. B., and C. M. Balch. 1982. A comparison of PGE2 effects on human suppressor cell function and on interleukin-2 function. J. Immunol. 129:2469-2472.

26. Tsoukas, C. D., J. Lambris, M. Lotz, M. A. Valentine, J. H. Vaughan, and D. A. Carson. 1984. Lymphocyte mitogenesis induced by monoclonal antibodies to the T3 complex. Differential modulation by human IgG. Cell. Immunol. 89:66-74.

27. Burmester, G. R., D. T. Y. Yu, A. M. Irani, H. G. Kunkel, and R. J. Winchester. 1981. Ia+ T cells in synovial fluid and tissues of patients with rheumatoid arthritis. Arthritis Rheum. 24:1370-1376.

28. Burmester, G. R., B. John, M. Gramatzki, J. Zacher, and J. R. Kalden. 1984. Activated $T$ cells in vivo and in vitro: divergence in expression of Tac and Ia antigens in the nonblastoid small $\mathrm{T}$ cells of 
inflammation and normal T cells activated in vitro. J. Immunol. 133: 1230-1234.

29. Fox, R. I., S. Fong, N. Sabharwal, S. A. Carstens, P. C. Kung, and J. H. Vaughan. 1982. Synovial fluid lymphocytes differ from peripheral blood lymphocytes in patients with rheumatoid arthritis. J. Immunol. 128:351-354.

30. Galili, U., L. Rosenthal, N. Galili, and E. Klein. 1979. Activated $T$ cells in the synovial fluid of arthritic patients: Characterization and comparison with in vitro activated human and murine $T$ cells in cooperation with monocytes in cytotoxicity. J. Immunol. 122:878-883.

31. Scala, G., Y. D. Kuang, R. E. Hall, A. V. Muchmore, and J. J. Oppenheim. 1984. Accessory cell function of human B cells. I. Production of both interleukin-1-like activity and interleukin-1 inhibitory factor by an EBV-transformed B cell line. J. Exp. Med. 159:1637-1652.

32. Lotz, M., C. D. Tsoukas, S. Fong, C. A. Dinarello, D. A. Carson, and J. H. Vaughan. 1986. Release of lymphokines after Epstein-Barr virus infection in vitro: II. A monocyte derived inhibitor of interleukin1 downregulates the production of interleukin- 2 and gamma interferon in rheumatoid arthritis. J. Immunol. 136:3643-3648.
33. Dinarello, C. A., L. J. Rosenwasser, and S. M. Wolff. 1981. Demonstration of a circulating suppressor factor of thymocyte proliferation during endotoxin fever in humans. J. Immunol. 127:2517-2519.

34. Liao, Z., R. S. Grimshaw, and D. L. Rosenstreich. 1984. Identification of a specific interleukin 1 inhibitor in the urine of febrile patients. J. Exp. Med. 159:126-136.

35. Wood, D. D., E. J. Ihrie, C. A. Dinarello, and P. L. Cohen. 1983. Isolation of an interleukin-1-like factor from human joint effusions. $A r$ thritis Rheum. 26:975-983.

36. Arend, W. P., F. G. Joslin, and R. J. Massoni. 1985. Effects of immune complexes on production by human monocytes of interleukin 1 or an interleukin 1 inhibitor. $J$. Immunol. 134:3868-3875.

37. Rodgers, B. C., D. M. Scott, J. Mundin, and J. G. P. Sissons. 1985. Monocyte-derived inhibitor of interleukin 1 inducted by human cytomegalovirus. J. Virol. 55:527-532.

38. Lotz, M., C. D. Tsoukas, P. K. Hench, D. A. Carson, and J. H. Vaughan. 1986. Release of lymphokines following Epstein-Barr virus infection in vitro of blood lymphocytes from patients with autoimmune diseases. Trans. Assoc. Am. Physicians. In press. 